\title{
A MEMÓRIA EM (VIAS DE) EXTINÇÃO: A SOCIEDADE DE CONTROLE EM FAHRENHEIT 451
}

\author{
Mariane Pereira Rocha \\ Mestranda em Literatura Comparada pela UFPel - Bolsista CAPES \\ marianep.rocha@gmail.com
}

Ariane Ávila Neto de Farias Doutoranda em Letras - História da Literatura pela FURG arianenetof@gmail.com

\author{
Ânderson Martins Pereira \\ Doutorando em Letras - Estudos Literários pela UFRGS - Bolsista CAPES \\ andersonmartinsp@gmail.com
}

\section{RESUMO}

O presente artigo busca refletir sobre a relação entre memória e controle na obra Fahrenheit 451 de Ray Bradbury e discutir sobre como essas questões se atrelam às mazelas da sociedade moderna. Para tal, este estudo utiliza-se das contribuições de Benjamin (1996), Claeys (2010), Hobbes (1904 [1651]) e Ribeiro (2015). Este artigo justifica-se por contribuir com os estudos sobre a memória e com a literatura distópica, os quais têm se destacado nas últimas décadas e têm tornado disponíveis novas ferramentas para melhor entender a atualidade, bem como as sociedades das quais eles se originam.

Palavras-chave: Bradbury; distopia; memória; controle.

\section{ABSTRACT}

INTRODUÇÃO
This essay aims to reflect about the relation between memory and control in Fahrenheit 451 by Ray Bradbury and to discuss about how these issues are linked with the modern society problems. Therefore, this study will use Benjamin (1996), Claeys (2010), Hobbes (1904 [1651]) and Ribeiro (2015) contributions. This article contributes to the study about memory and with dystopian literature, which have been highlighted in the recent decades, allowing the emergence of new tools to better understand the modernity as well as the new societies that they create.

Keywords: Bradbury; dystopia; memory; control. 
O rompimento com a memória é uma característica corrente em muitas distopias. Quando as pessoas desconhecem realidades melhores, bem como experimentos e características nocivas da sociedade em que vivem, são mais facilmente controladas. Para uma melhor visão acerca da obra aqui analisada, são necessárias algumas incursões teóricas sobre o gênero distopia e sua conexão com a sociedade. O nome distopia foi usado pela primeira vez pelo filósofo John Stuart Mill em uma de suas falas no parlamento inglês no ano de 1868; o conceito, porém, só ganhou certo destaque no século XX. A distopia é um gênero essencialmente arraigado à sociedade e dentre suas características mais marcantes estão a discussão de valores éticos ou morais e a denúncia de suas possíveis deturpações. Nesse sentido, as distopias criam uma sociedade atroz, na qual os indivíduos que ali coexistem carecem de direitos básicos, prerrogativas essenciais para o que se entende por condição humana nestes universos.

Vários textos têm buscado estabelecer padrões e lidar com as manifestações propostas pelo gênero desde seu surgimento; tal marco, segundo Gregory Claeys (2010, p.110), estaria localizado em meados de 1756 com a publicação da obra Vindication of Natural Society de Edmund Burke. Desde então, reflexões acerca de valores morais e éticos têm sido debatidas e atualizadas nestes textos e, por conseguinte, pelas teorias que buscam dar conta de tais narrativas. Existe uma tendência notável da distopia a possuir padrões temporais, a qual se encontra no fato de tais textos refletirem as sociedades das quais são produto.

Fahrenheit 451, publicado pela primeira vez em 1953, retrata uma sociedade onde livros são proibidos; possuir ou ler um livro é considerado crime e os bombeiros são encarregados de queimar todo e cada exemplar que encontrarem. Cinema, fotografia e 
outras formas de arte também não estão mais presentes, tendo sido substituídas pelo entretenimento das telenovelas.

Durante a narrativa, acompanhamos a história de Guy Montag, um bombeiro que nos é apresentado como uma pessoa comum nessa sociedade: cumpre seu dever e sente-se feliz desempenhando sua função: "queimar era um prazer" (BRADBURY, 2009, p. 15), sem pensar no porquê da execução de seu trabalho. Mas, aos poucos, assistimos a personagem se desenvolver e, a partir do momento em que conhece Clarisse Mclellan, começar a questionar o vazio da vida que ele e as pessoas ao seu redor levam: uma vida movida pelo entretenimento e pela superficialidade das relações.É dessa forma que a narrativa vai se desenvolvendo, tendo como pilar os conflitos internos de Montag e as represálias que ele acaba sofrendo, visto que a sociedade de Bradbury considerava toda forma de reflexão e contestação como subversividades que fariam mal ao sistema como um todo e, sendo assim, estas deveriam ser fortemente repreendidas.

A memória e o conhecimento decorrente do processo de lembrar são instrumentos de poder no manejo da sociedade. O filosofo inglês Thomas Hobbes, no livro Leviathan or The Matter, Forme and Power of a Common Wealth Ecclesiastical and Civil, escrito em 1651, pontua que conhecimento é poder.Nas distopias,onde as discussões sobre o poder nas sociedades estão sempre presentes, vamos observar que governos totalitários vão usar da memória como uma ferramenta para reprimir e coagir a população. Hobbes acreditava também que a sociedade só poderia se despojar da ameaça da guerra com um governo forte e indivisível, porém, neste quesito, as conexões com distopias se distanciam, já que estes 
governos totalitários muitas vezes não evitam batalhas, mas se estabelecem a partir delas, como é o caso de 1984 de George Orwell e We escrito por Yevgeny Zamyatin.

Ainda assim, a conexão direta entre conhecimento e poder posta por Hobbes é facilmente observável nas distopias que utilizam o saber ou sua restrição como arma contra as massas. Em Fahrenheit 451, a tentativa de extirpação do conhecimento se inicia pela destruição dos livros: sabe-se que os bombeiros não apagam o fogo, mas oproduzem, dilacerando toda forma de conhecimento ou arte que não a veiculada ao/pelo governo.

Outro fator importante é a institucionalização de crime em relação ao conhecimento; o fato de portar tais objetos de conhecimento e/ou disseminá-los é contra a lei. Não obstante, não é só o fato de ser contra a lei que ocasiona um problema, mas a obediência cega à lei e às ordens do governo pela população. As pessoas não apenas acreditavam que o conhecimento era algo ruim, como delatavam pessoas para proteger este sistema. Contudo, ao final da obra, é através da memória que os indivíduos encontram uma maneira de burlarem o sistema opressor, bem como desenvolvem um ideal de comunidade.

\section{A LITERATURA EM (VIAS DE) EXTINÇÃO}

Benjamin, ao diferenciar experiência (erfahrung) e vivência (erlebnis), vai definir a primeira como "a matéria da tradição tanto na vida privada quanto na coletiva" (1991, p. 105), ou seja, essa capacidade humana de dialogar e aprender com o passado. Capacidades estas que, na modernidade, estão se esvaindo. Nas palavras de Benjamin: "está claro que as ações da experiência estão em baixa, e tudo indica que continuarão caindo até que seu valor desapareça de todo" (1996, p. 198). 
Estamos mais ricos em vivências -ninguém pode negar a quantidade de situações que vivenciamos diariamente -, mas não conseguimos transformar essas vivências em experiências. Benjamin (1991) explica que essas situações cotidianas que vivenciamos, frequentemente violentas - choques -, são recebidas com tanta frequência durante o dia a dia que a mente acaba se amortecendo, tornando-se insensível a elas, como no caso extremo dos soldados, que conforme nos lembra o filósofo, voltaram da guerra emudecidos, sem conseguirem transmitir aos outros as situações que viveram durante esse período vivências que não foram transformadas em experiências.

Benjamin ainda afirma que é esse processo de insensibilização que distancia os leitores modernos da experiência poética:

O fato do choque ser assim amortecido e aparado pelo consciente emprestaria ao evento que o provoca o caráter de experiência vivida em sentido restrito. E, incorporando imediatamente esse evento ao acervo das lembranças conscientes, o tornaria estéril para a experiência poética (BENJAMIN, 1991, p. 110). ${ }^{1}$

Em Fahrenheit 451 fica evidente como essa dificuldade em se conectar com a experiência poética acaba se tornando peça fundamental para o desaparecimento da Literatura na sociedade. No começo da narrativa, tem-se a ideia de que os livros são proibidos em função de uma lei estabelecida pelo Estado. Porém, ao longo da narrativa vamos entendendo as sutilezas envolvidas nesse processo, conforme no excerto abaixo, retirado de uma conversa entre Montag e seu chefe, Beatty:

\footnotetext{
${ }^{1}$ Nesse texto especificamente Benjamin está usando experiência poética para se referir ao gênero lírico, mas respaldada por seu texto "O narrador" (1996) usamos neste artigo experiência poética para nos referirmos à literatura de forma geral, incluindo os gêneros narrativos.
} 
Aí está, Montag. A coisa não veio do governo. Não houve nenhum decreto, nenhuma declaração, nenhuma censura como ponto de partida. A tecnologia, a exploração das massas e a pressão das minorias realizaram a façanha, graças a Deus. Hoje, graças a elas, você pode ficar o tempo todo feliz (BRADBURY, 2009, p. 88).

Em outro momento, é possível perceber de que forma, na prática, a tecnologia parece ter assumido um papel central nessa nova sociedade, afastando ainda mais as personagens de algum resquício de conexão com a experiência poética. Mildred, esposa de Montag, é viciada em novelas, que, nesse futuro distópico, são interativas, o telespectador conversa com as personagens, criando uma espécie de "família".

Mildred bateu o pé num livro.

-Livros não são pessoas. Você lê e eu olho em volta, mas não há ninguém!

Ele olhou para o salão, morto e cinzento como as águas de um oceano que transbordaria de vida se eles acendessem o sol eletrônico.

- Agora - disse Mildred -, minha "família" é de pessoas. Elas me contam coisas: eu rio, eles riem! E as cores, então?

- Sim, eu sei.

- E, além disso, se o capitão Beatty ficasse sabendo sobre esses livros... - Ela refletiu um pouco. Seu rosto foi ficando assustado e, depois, apavorado. - Ele pode chegar e queimar a casa e a "família". Isso é terrível! Pense em nosso investimento. Por que eu deveria ler? Para quê? (BRADBURY, 2009, p. 107).

Essa família imaginada surge como um "sonho", uma resposta à pobreza de experiência que as personagens carregam dentro de si. Conforme afirmou Benjamin "ao cansaço segue-se o sonho e, não é raro que o sonho compense a tristeza e o desânimo do dia, realizando a existência inteiramente simples e absolutamente grandiosa que não pode ser realizada durante o dia, por falta de forças" (1996, p. 118). 
Dessa forma, percebemos que o desaparecimento dos livros começa por uma desconexão das pessoas inseridas naquela sociedade com a experiência poética antes de que por uma proibição governamental, conforme nos lembra a personagem Faber: “Lembre-se, os bombeiros raramente são necessários. O próprio público deixou de ler por decisão própria" (BRADBURY, 2009, p. 126-127). Mas, conforme será aprofundado nos próximos capítulos, se o ato de deixar de lado a literatura parte dos cidadãos, o governo tampouco age de forma inocente ao instaurar o regime de "queima de livros", com todo o significado simbólico que esse ato carrega.

\section{AS TELENOVELAS ANESTÉTICAS}

Como já mencionado anteriormente, as novelas ocupam um lugar central nas vidas dos cidadãos da distopia de Bradbury. Eles não somente as assistem e participam de suas narrativas interativas o tempo todo, mas transformam essas histórias em realidade, consideram as personagens da novela suas próprias famílias, enquanto mantém relações superficiais com as pessoas que se relacionam fisicamente. "Como uma pessoa fica tão vazia?, perguntou a si mesmo. Quem esvazia a gente? [...] Ora, pensando bem não havia uma parede ${ }^{2}$ entre ele e Mildred? Literalmente, não apenas uma, mas, até agora, três!" (BRADBURY, 2009, p. 69).

Esse entretenimento talvez represente aquilo que Benjamin definiu como "estetização da política". Através de narrativas bastante violentas, as personagens parecem ter cada vez mais dificuldade para enxergar uma realidade fora das paredes.

Um minuto depois, um desenho animado mostrava os Três Palhaços Brancos se esquartejando mutuamente ao som de enormes gargalhadas. Dois minutos mais e o salão resvalou da cidade para

${ }^{2}$ Parede é como as personagens se referem aos televisores que ocupam toda a dimensão de uma parede. 
os carros a jato circulando ferozmente numa arena, colidindo e recuando e colidindo entre si novamente. Montag viu vários corpos voarem pelo ar (BRADBURY, 2009, p. 136).

Em uma sociedade onde o choque se tornou a norma (BENJAMIN, 1991) e estes choques estão sendo exibidos a todo momento nas televisões, queimar livros - e até mesmo pessoas junto a eles - não parece ser algo que mereça preocupação. Benjamin afirma que nesses cenários a "autoalienação chegou a um ponto que lhe permite vivenciar a própria destruição como um prazer estético de primeira ordem.Essa é a situação em que se encontra a estetização da política empreendida pelo fascismo" (apud BUCK-MORSS, 1996, p. 13).

Se faz ainda importante lembrar que essa é uma sociedade em que nenhum tipo de arte existe mais. Quando Buck-Morss comenta que Benjamin considerava a politização da arte como a resposta para a estetização da política já que o papel dela é "desfazer a alienação do aparato sensorial do corpo, restaurar o poder instintual dos sentidos corporais humanos em nome da auto-preservação da humanidade" (1996, p. 12), não encontramos uma correspondência em Fahrenheit 451, pois além das novelas e o trabalho, eles não tinham outras atividades:

-Ah, mas já temos muitas horas de folga.

-Horas de folga, sim. Mas e tempo para pensar? Quando você não está dirigindo a cento e sessenta por hora, numa velocidade em que não consegue pensar em outra coisa senão no perigo, está praticando algum jogo ou sentado em algum salão onde não pode discutir com o televisor de quatro paredes. Por quê? O televisor é "real". É imediato, tem dimensão. Diz o que você deve pensar e o bombardeia com isso. Ele tem que ter razão. Ele parece ter muita razão. Ele o leva tão depressa às conclusões que sua cabeça não tem tempo para protestar: "Isso é bobagem!" 
-Somente a "família" é "gente".

-Como disse?

-Minha mulher diz que os livros não são "reais"(BRADBURY, 2009, p. 122).

Fica evidente, nessa passagem, que a televisão substitui as artes de forma geral, e, assim, as personagens não encontram uma forma de recuperar os instintos dos sentidos corporais, sendo muito mais difícil resistir ou enfrentar a alienação.

\section{O LIVRO QUE QUEIMA: UM MAL DE ARQUIVO}

Conforme mencionado na seção 1 deste texto, as personagens de Fahrenheit 451 deixaram de ler por uma questão individual, por um desencontro de suas vivências com a experiência poética. Entretanto, parte do Estado a iniciativa de censurar, coibir, proibir e, talvez a prática mais significativa nessa narrativa, incinerar os livros. A instituição responsável por esse controle, o Departamento de bombeiro é, inclusive, uma instituição mantida pelo Estado. Entre as regras desse departamento estavam:

1a REGRA. Atenda prontamente o telefone.

2a REGRA. Comece o fogo rapidamente.

3a REGRA. Queime tudo

4a REGRA. Reporte-se imediatamente ao posto dos bombeiros.

5a REGRA. Fique sempre alerta a outros alarmes (BRADBURY, 2009, p. 57).

A queima de livros, nesse sentido, não era um ato ingênuo ou desprovido de maiores sentidos, mas ao contrário, era um ato político, já que conforme discutimos anteriormente, o controle da memória é parte significativa da manutenção do poder em um governo totalitário. Queimar os livros, nesse sentido, significava apagar grande parte da memória 
coletiva e do saber adquirido por aquela e por outras sociedades, bem como, impossibilitar que conteúdo contrário às posições governamentais chegasse aos cidadãos. Eles optam, contudo, por eliminar todas as obras, já que, afinal, todas elas possuíam o poder de promover algum tipo de reflexão nos cidadãos. Era de interesse do governo mantê-los distraídos e "felizes", pois assim não questionariam a forma como o país estava sendo conduzido, conforme fica claro na fala de Beatty:

Se não quiser um homem politicamente infeliz, não lhe dê os dois lados de uma questão para resolver; dê-lhe apenas um. Melhor ainda, não Ihe dê nenhum. Deixe que ele esqueça de que há uma coisa como a guerra. Se o governo é ineficiente, despótico e ávido por impostos, melhor que ele seja tudo isso do que as pessoas se preocuparem com isso (BRADBURY, 2009, p. 92).

Nota-se, dessa forma, que a visão de livro implícita em Fahrenheit 451 vai de encontro com a leitura que Derrida fazde "arquivo", quando este aponta que "não há poder político sem o controle sobre os arquivos, sem o controle sobre a memória" (apud ASSMAN, 2011 [1995]), ou seja, os livros seriam arquivos investidos de poder e que possuem a capacidade de carregar memória. Há, na distopia de Bradbury, um temor que a leitura cause desestabilização a um sistema imposto pelo Estado e, se pensarmos conforme sugere Assman (2011) baseada em suas leituras de Derrida, em termos de abertura e fechamentos, vemos na distopia de Bradbury um governo totalmente repressivo e opressor que faz uso do controle da memória para manter a sociedade estabelecida.

\section{CONSIDERAÇÕES FINAIS}

Quando Ray Bradbury publicou Fahrenheit 451 em 1953, imaginou que suas personagens viviam na virada/começo do século $\mathrm{XXI}$, em um tempo similar com o qual vivemos agora. É possível estabelecer diversos paralelos entre a sociedade distópica de 
Bradbury e o controle midiático e predomínio das tecnologias que, de certa forma, vêm sendo bastante presente desde os anos 90 em nossa sociedade. É por isso que se torna tão coerente relacionar essa narrativa com diversos pontos discutidos por Walter Benjamin, que pensou tão profundamente sobre as transformações que nosso mundo vinha sofrendo durante a modernidade. Bradbury e Benjamin escreveram em épocas bastante similares e ambos parecem ter acertado em suas previsões para o futuro e, falando a partir de seu tempo, em caracterizar o que viria a ser este período pós modernidade.

Ao falar de arquivo e memória, Bradbury nos mostra que o Estado de Fahrenheit 451 era eficaz em controlar a população - importante lembrar que esse estado não hesitava caso tivesse que queimar junto aos livros o arquivo-corpo também -, e, mais uma vez, nos remete à questões bastante atuais, como a perenidade de todo arquivo e as limitações que a sociedade ainda tem em relação a seleção e preservação de sua memória cultural.

\section{REFERÊNCIAS}

ASSMAN, Aleida.Espaços da recordação: formas e transformações da memória cultural. Trad. Paulo Soothe. São Paulo: Editora Unicamp, 2011.

BENJAMIN, Walter. "A obra de arte na era de sua reprodutibilidade técnica". In: Magia e técnica, arte e política: ensaios sobre literatura e história da cultura. Obras Escolhidas Vol 1. Tradução: Sérgio Rounaet. São Paulo: Brasiliense, 1996.

BENJAMIN, Walter. "O narrador". In: Magia e técnica, arte e política: ensaios sobre literatura $e$ história da cultura. Obras Escolhidas Vol 1. Tradução: Sérgio Rounaet. São Paulo: Brasiliense, 1996.

BENJAMIN, Walter. "Sobre o conceito de história". In: Magia e técnica, arte e política: ensaios sobre literatura e história da cultura. Obras Escolhidas Vol 1. Tradução: Sérgio Rounaet. São Paulo: Brasiliense, 1996.

BENJAMIN, Walter. "Experiência e pobreza". In: Magia e técnica, arte e política: ensaios 
sobre literatura e história da cultura. Obras Escolhidas Vol 1. Tradução: Sérgio Rounaet. São Paulo: Brasiliense, 1996.

BENJAMIN, Walter. "Alguns temas em Baudelaire" In: BAUDELAIRE, Charles. Um lírico no auge do capitalismo. Tradução: José Carlos Barbosa. São Paulo: Brasiliense, 1991.

BRADBURY, Ray. Fahrenheit 451. Tradução: Cid Knipel. São Paulo: Globo, 2009.

BUCK-MORSS, Susan. "Estética e anestética: 'O Ensaio sobre a obra de arte de Walter Benjamin' reconsiderado". Santa Catarina: Editora UFSC, 1996. p. 11-76

CLAEYS, Gregory. "The origins of dystopia: Wells, Huxley and Orwell". In: CLAEYS, Gregory (Ed.). The Cambridge Companion to Utopian Literature. Cambridge: Cambridge University Press, 2010. p. 107-131.

HOBBES, Thomas. Leviathan or the matter, forme \& power of a commonwealth, ecclesiasticall and civill.London: Cambridge University Press, 1904 [1651]

RIBEIRO, Helano. "O apagamento do corpo-arquivo". Disponível em: <https://periodicos.ufsm.br/LA/article/view/18261> Acesso em: 10/08/17

Artigo recebido em: 28 de maio de 2018. Artigo aprovado em: 09 de julho de 2018. 